\title{
Correlates of screen time and mediators of differences by parental education among adolescents
}

\author{
Mekdes K. Gebremariam', Sigrun Henjum², Laura Terragni ${ }^{2}$ and Liv Elin Torheim² ${ }^{2}$ (D)
}

\begin{abstract}
Background: Existing literature shows that there is an inverse association between socioeconomic position and screen time among adolescents. What is less known is the mechanism behind these differences. The study aimed to explore individual, interpersonal and neighborhood environmental correlates of total screen time (TST) among adolescents and to assess their mediating role in the association between parental education and TST.
\end{abstract}

Methods: A cross-sectional study including 706 adolescents (mean age of 13.6 (SD =0.3)) was used to collect data at schools through an online questionnaire. Multiple regression analyses were used to explore factors associated with TST. Mediation analyses were conducted to assess whether these factors mediated the association between parental education and TST.

Results: Multiple linear regression analyses, adjusted for gender and age, showed that parental modelling of TV and movie streaming, TV/movie streaming during dinner and access to screens were positively related to TST. Selfefficacy towards limiting TV and movie streaming, self-efficacy towards limiting computer/electronic game use, and the perceived opportunities for physical activity in the neighborhood were inversely related to total screen time. All of these factors except self-efficacy towards limiting TV and movie streaming mediated the association between parental education and TST.

Conclusions: The study identified several modifiable factors at the individual, interpersonal and neighborhood environmental levels that can be targeted in interventions aimed at decreasing screen time among youth in general and among those with a low socioeconomic position in particular.

Keywords: Sedentary behavior, Correlates, Mediators, Social inequalities, Adolescents

\section{Background}

Research focusing on sedentary behaviors (SBs) has received increased attention in recent years due to concerns about excessive time spent sedentary in modern societies. Sedentary behavior is defined as any waking behavior characterized by an energy expenditure $\leq 1.5$ METs while in a sitting or reclining posture [1]. Screen-

\footnotetext{
* Correspondence: livtor@oslomet.no

${ }^{2}$ Department of Nursing and Health Promotion, Faculty of Health Sciences, OsloMet - Oslo Metropolitan University, 0130 Oslo, Norway

Full list of author information is available at the end of the article
}

based SBs are among these behaviors and are highly prevalent among youth [2]. SBs are associated with several adverse health impacts among youth [3, 4]. A review of 235 studies representing 1,657,064 unique participants from 71 different countries found that screen time and television (TV) viewing were positively associated with unfavorable body composition and higher clustered cardiometabolic risk scores. TV viewing and video game use were positively associated with unfavorable behavioral conduct. Screen time was inversely related to fitness and self-esteem [3]. Associations between SB and

C C The Author(s). 2020 Open Access This article is licensed under a Creative Commons Attribution 4.0 International License, which permits use, sharing, adaptation, distribution and reproduction in any medium or format, as long as you give appropriate credit to the original author(s) and the source, provide a link to the Creative Commons licence, and indicate if changes were made. The images or other third party material in this article are included in the article's Creative Commons licence, unless indicated otherwise in a credit line to the material. If material is not included in the article's Creative Commons licence and your intended use is not permitted by statutory regulation or exceeds the permitted use, you will need to obtain permission directly from the copyright holder. To view a copy of this licence, visit http://creativecommons.org/licenses/by/4.0/ The Creative Commons Public Domain Dedication waiver (http://creativecommons.org/publicdomain/zero/1.0/) applies to the data made available in this article, unless otherwise stated in a credit line to the data. 
health outcomes are however not always consistent [4]. In addition, SBs track moderately from childhood and adolescence [5]; early interventions targeting these behaviors are thus vital. In order to inform such interventions, there is a need to identify key correlates of SBs. Existing evidence has identified parental modeling [6-8], parental rules $[7,9]$, the presence of a bedroom TV [6], more access to electronic devices $[7,9]$ and ethnicity $[6$, $7,9,10]$ as correlates of screen-based SBs among youth. A recent systematic review focusing on neighborhood environmental correlates of SB found that traffic, availability of a favorable environment for PA and higher residential density were associated with lower levels of SB among adolescents [11]; the authors however concluded that there were few studies investigating the association between SB and neighborhood characteristics, making the evidence limited [11]. There are indeed multiple levels of influence on health behaviors as postulated in the social ecological model of health behaviors including social, psychological and environmental influences [12]. The best approach to change behavior is through multi-level interventions, thus knowledge about important factors at these different levels of influence is vital [12]. The need to include more screen-based SBs including more contemporary screen activities has also been highlighted repeatedly in the literature.

In addition, socioeconomic differences in screen-based SB have been documented in several studies including Norwegian studies $[6,7,9,10,13]$. Such differences can lead to inequalities in SB-related adverse health outcomes. In this regard, a recent systematic review documented that screen-based SBs are consistent mediators of socioeconomic differences in body weight among youth [14]. Identifying mediators of socioeconomic differences in screen time would thus provide useful information for interventions aimed at tackling inequalities in obesity and other adverse health effects of SBs. A mediator represents an intervening variable in the causal pathway between exposure and outcome [15]. Socioeconomic inequalities related to factors such as education, income, employment and occupation might be associated with unequal exposure to risk factors and unequal access to health-promoting resources [16]. Thus, correlates of SBs at the different levels of the social ecological model that vary by socioeconomic position (SEP) have the potential to mediate socioeconomic differences in SB. The few existing studies exploring mediators of socioeconomic differences in SB included in a review identified the following mediators: frequency of eating dinner and snacks in front of TV, parental TV coviewing and regulation, availability of media in bedroom and parental modelling [13]. Only one of these five studies used total screen time (TST) as an outcome measure [17]. More studies exploring mediators of socioeconomic differences in SB were called for, namely studies including a broader range of SBs and exploring the association between SEP and environmental correlates [13].

Against this background, the aim of the present study was to assess individual, interpersonal and perceived environmental correlates of TST among adolescents and to explore whether these correlates mediated parental educational differences in TST.

\section{Methods}

\section{Design and sample}

The participants in this study were pupils from eleven secondary schools participating in the Environmental determinantS of dietary BehaviorS among adolescENtS (ESSENS) cross-sectional study. All twelve secondary schools in the Øvre Romerike region located in the Eastern part of Norway were invited to participate in the study, and eleven accepted the invitation. In total, 1163 adolescents in the eighth grade were invited to participate in this study and a total of 781 (67\%) received parental consent for participation. A total of 742 adolescents (64\% of those invited and $95 \%$ of those with parental consent) participated in the study which was conducted at schools between October and December 2016.

\section{Data collection and measures}

A web-based questionnaire was used to collect data from the adolescents. The questionnaires were filled in at school, and took approximately $30-45 \mathrm{~min}$ to complete. The questionnaire was pre-tested for clarity and length among a group of adolescents of the same age as the study participants $(n=23)$, prior to the main study.

\section{Outcome variable}

Screen-based sedentary behaviors The following questions with pre-coded answer categories were used to assess screen time: How many hours do you usually watch TV, as well as DVDs, videos or movies on the PC, telephone or tablet in your spare time on a normal weekday? How many hours do you usually play computer games, games on a game console (e.g. PlayStation, Xbox, GameCube), games on a tablet or mobile phone on a normal weekday? How many hours do you usually use a computer, tablet or phone for activities such as chatting, internet, emailing, Facebook and Instagram on a normal weekday? The same questions were asked for a normal weekend day. The answer categories ranged from none to $4 \mathrm{~h}$ or more per day for all questions. Separate weekly scores for the different screen-based SB were calculated by summing hours reported for an average weekday (multiplied by five) and an average weekend day (multiplied by 2), and then summed to create a TST variable. 
The screen time measures were adopted and modified (to reflect recent patterns in screen-based activities) from previous measures with evidence of moderate construct validity [18] and moderate test-retest reliability $[18,19]$.

\section{Potential mediators}

Self-efficacy towards watching TV, as well as DVD, videos or movies on phone or tablet was assessed using a five items scale (e.g. How sure are you that you can ... limit watching TV as well as DVD, videos or movies on phone or tablet to $1 \mathrm{~h}$ at least one school day?). Selfefficacy towards use of computer/electronic games was assessed using a five items scale (e.g. How sure are you that you can ... limit playing computer games including game consoles, games on mobile or tablet to $1 \mathrm{~h}$ at least one school day?). Both weekday and weekend screen use were included in the self-efficacy questions [20].

Screen viewing during meals was assessed using three questions about how often the adolescents watched TV, DVDs, video or movies on phone or tablet during breakfast, lunch and dinner. There were 5 response options ranging from "never" to "always".

Parental modeling was assessed using the question: How often do your parents watch TV as well as DVDs, video or movies on phone or tablet? There were 5 response options ranging from "never" to "always".

Parental co-viewing was assessed using the question: How often do you watch TV as well as DVDs, video or movies on phone or tablet together with your parents? There were 7 response options ranging from "never" to "every day, more than once/day".

The questions assessing screen viewing during meals, parental modeling and parental co-viewing were adapted from previous measures with evidence of adequate testretest reliability [18].

Access to screens was assessed using three questions: Do you have a TV in your bedroom? Do you have your own computer? Do you have your own tablet? The questions had a yes (1) and no (0) response options. The answers to the questions were summed up to create a variable assessing total access to screens.

Neighborhood safety was assessed using the question: It is safe to walk or play alone in my neighborhood during the day (there were 5 response options ranging from "totally agree" to "totally disagree").

Perceived opportunities for PA in neighborhood was assessed using a Likert-type scale (There are places in the vicinity of my home I can go out and play; there are other children nearby home to go out and play with).

Neighborhood facilities for PA were explored using the statement: "there are playgrounds and parks near my home where I can play/be physically active" (5 response options ranging from "totally agree" to "totally disagree").

The items assessing neighborhood safety, perceived opportunities for PA in neighborhood, neighborhood facilities for PA were adopted from measures developed by Ommundsen et al. [21].

\section{Parental education}

Information on parental education was gathered as part of the parental informed consent for the adolescent. It was categorized into: low (12 years of education or less, which corresponded to secondary education or lower) and high (13 years of education and more, which corresponded to university or college attendance). Educational status of the parent with the longest education or else the one available was used in the analyses.

\section{Statistical analyses}

The analytical sample for this study was made up of 706 participants with information on parental education (36 participants with missing data on parental education were excluded). Since schools were the unit of measurement in this study, we checked for clustering effect through the Linear Mixed Model procedure. Only 1\% of the unexplained variance in TST was at the school level. Hence, adjustment for clustering effect was not done. Descriptive analyses were first conducted. Univariable linear regression analyses were then used to explore factors at the individual, interpersonal, family and neighbourhood levels associated with TST. Thereafter, factors significant in the univariable regression analyses were entered in multiple regression models.

Mediation analyses were thereafter conducted. Figure 1 illustrates the multiple mediation model used. In the multiple mediation analysis, the ai-paths represent the association between parental education and each mediator. The bi-paths represent the association between the mediators and TST (adjusted for parental education and the other mediators). The c' path represents the association between parental education and TST when adjusted for mediators. The c path represents the total effect of parental education on TST. Gender and age were controlled for in the analyses. Bootstrap corrected CIs were calculated for indirect effects (a*b). Bootstrapping (5000 samples) was conducted using the PROCESS macro 3.4. for SPSS by Andrew Hayes [22]. Analyses were conducted using SPSS version 25 . The significance level was set to 0.05 .

\section{Results}

Table 1 shows the characteristics of participants. Fifty four percent of participants were females and $40 \%$ had parents with low education. Parental education was significantly inversely related to TST. There were 


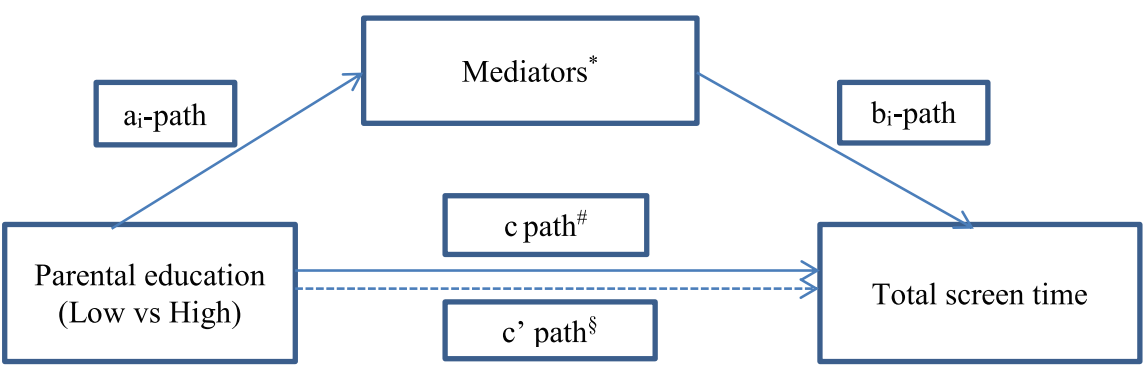

${ }^{*}$ parental modelling of TV and movie streaming, self-efficacy towards limiting computer/electronic game use, TV/movie streaming during dinner, access to screens and the perceived opportunities for PA in the neighborhood

\# adjusted for age and gender

$\S$ adjusted for age, gender and mediators

Fig. 1 Mediation model

socioeconomic differences in all three different screen based activities used to compute total screen time (results not shown). Mean scores for self-efficacy to limit computer/electronic game use, perceived neighborhood opportunities for PA and perceived neighborhood facilities were significantly higher for those with high parental education compared to those with low parental education. Mean scores for TV/movie streaming during lunch and dinner, parental modeling and access to screens were significantly lower for those with high parental education compared to those with low parental education.

Results of multiple linear regression analyses, adjusted for gender, age and parental education, showed that parental modelling of TV and movie streaming $(B=4.44$ (CI: $2.90,5.98)$ ), $\mathrm{TV} /$ movie streaming during dinner $(\mathrm{B}=1.10(0.07,2.13))$ and access to screens $(\mathrm{B}=1.81(\mathrm{CI}$ : $0.42,3.20)$ ) were positively related to TST. Self-efficacy

Table 1 Characteristics of participants and parental educational differences

\begin{tabular}{|c|c|c|c|c|}
\hline & Total sample $(n=702)^{a}$ & Low parental education & High parental education & $p^{* *}$ \\
\hline Age (years) & $13.64(0.3)$ & $13.66(0.3)$ & $13.63(0.3)$ & 0.33 \\
\hline Gender (\% female) & 54.0 & 54.9 & 53.3 & 0.70 \\
\hline Total screen time (hrs/wk) & $36.34(17.51)$ & $41.14(18.54)$ & $33.24(16.12)$ & $<0.001$ \\
\hline Self-efficacy to limit TV/movie streaming & $4.84(3.28)$ & $4.56(3.46)$ & $5.01(3.14)$ & 0.08 \\
\hline Self-efficacy to limit computer/electronic games & $5.94(3.91)$ & $5.53(4.12)$ & $6.22(3.74)$ & 0.03 \\
\hline TV/movie streaming during breakfast & $2.40(1.35)$ & $2.51(1.38)$ & $2.32(1.32)$ & 0.073 \\
\hline TV/movie streaming during lunch & $2.34(1.23)$ & $2.45(1.25)$ & $2.25(1.19)$ & 0.030 \\
\hline $\mathrm{TV} / \mathrm{movie}$ streaming during dinner & $2.14(1.26)$ & $2.36(1.30)$ & $1.98(1.18)$ & $<0.001$ \\
\hline Co-viewing with parents & $3.79(3.31)$ & $4.03(3.75)$ & $3.62(2.94)$ & 0.107 \\
\hline Parental modeling & $3.27(0.80)$ & $3.42(0.80)$ & $3.19(0.77)$ & $<0.001$ \\
\hline Access to screens & $1.93(0.87)$ & $2.07(0.84)$ & $1.84(0.88)$ & 0.001 \\
\hline Perceived opportunities for PA in neighborhood & $4.04(1.09)$ & $3.91(1.14)$ & $4.10(1.05)$ & 0.028 \\
\hline Neighborhood facilities & $3.65(1.57)$ & $3.41(1.65)$ & $3.75(1.52)$ & 0.006 \\
\hline Neighborhood safety & $4.66(0.79)$ & $4.62(0.78)$ & $4.69(0.81)$ & 0.247 \\
\hline
\end{tabular}

${ }^{a} n$ varies slightly between variables because of missing data

${ }^{* *} p$-value for differences between parental education groups (ANOVA and chi-squared test)

$P A$ physical activity 
towards limiting TV and movie streaming $(\mathrm{B}=-0.62$ (CI: $-1.03,-0.21)$ ), self-efficacy towards limiting computer/electronic game use $(\mathrm{B}=-1.18$ (CI: -1.54 , $0.82)$ ), and the perceived opportunities for physical activity (PA) in the neighborhood $(\mathrm{B}=-1.39$ (CI: -2.47 , $0.31)$ ) were inversely related to total screen time after adjusting for gender, age and parental education. The model explained $31 \%$ of the variability in TST (Table 2).

In the multiple mediation analyses, the factors found to mediate the association between parental education and TST were: parental modelling of TV and movie streaming $(\mathrm{ab}=-1.10(\mathrm{CI}:-1.76,-0.34))$, self-efficacy towards limiting the use of computer/electronic games $(\mathrm{ab}=-0.81(\mathrm{CI}:-1.69,-1.39))$, access to screens $(\mathrm{ab}=$ -0.40 (CI: $-0.84,-0.07$ ), TV/movie streaming during dinner $(\mathrm{ab}=-0.41(\mathrm{CI}:-0.97,-0.01)$ and perceived opportunities for PA in neighborhood $(\mathrm{ab}=-0.29$ (CI: $0.78,-0.01)$. Parental modeling and self-efficacy towards limiting the use of computer/electronic games were the strongest mediators (together mediated around 28\% of the association between parental education and TST). Access to screens, TV/movie streaming during dinner and perceived opportunities for PA in neighborhood had weaker mediating roles (Table 3).

\section{Discussion}

The study aimed to explore correlates of TST among adolescents and to assess their mediating role in the association between parental education and TST. Findings show that parental modelling of TV and movie streaming, TV/movie streaming during dinner and access to screens were positively related to TST. Self-efficacy towards limiting TV and movie streaming, self-efficacy towards limiting computer/electronic game use and the perceived opportunities for PA in the neighborhood were inversely associated with TST. All of these factors except self-efficacy towards limiting TV and movie streaming mediated the association between parental education and screen time.

Parental modeling $[6-8,23]$, access to electronic devices $[7,9]$ and eating meals in front of the TV [24] have previously been found to be associated with SB. The outcome of interest has however often been TV viewing and not TST, and more contemporary screen activities such as social media use were not included in most of these studies. Self-efficacy has been less explored in relation to its association with screen time, but is a widely documented predictor of health behaviors and is also emphasized in prominent theories of health behaviors such as the social cognitive theory [25]. The findings of the present study reflect its important role in influencing TST as well. The association between neighborhood PA opportunities and SB documented in this study contributes to the limited evidence in the literature. Perceived neighborhood safety was not associated with TST, in contrast to the findings of other studies that documented an impact of neighborhood safety on screen time. Timperio et al. found that neighborhood crime was associated with more time spent watching TV among adolescents [26]. Another study similarly documented that perception of low perceived neighborhood safety was associated with a higher screen time adolescent girls [27]. This could be due to the fact that parents might restrict PA outside the home when they perceive the neighborhood environment to be unsafe $[28,29]$. However, the present study was conducted in a predominantly semi-rural area in Norway where safety concerns are low, potentially leading to little variability between participants. Indeed, the mean of the variable was high and showed a ceiling effect, which might make associations difficult to detect.

Several of the correlates of SB included in this study differed by SEP, reflecting individual, familial and perceived environmental exposures that vary by socioeconomic position. Socioeconomic differences in parental

Table 2 Correlates of total screen time (hrs/week) among adolescents

\begin{tabular}{lll}
\hline & $\mathrm{B}$ and Cl & $p$ value \\
\hline Self-efficacy to limit TV/movie streaming & $-0.62(-1.03,-0.21)$ & 0.003 \\
Self-efficacy to limit computer/electronic games & $-1.18(-1.54,-0.82)$ & $<0.001$ \\
TV/movie streaming during breakfast & $0.76(-0.20,1.71)$ & 0.12 \\
TV/movie streaming during lunch & $1.01(-0.06,2.08)$ & 0.07 \\
TV/movie streaming during dinner & $1.10(0.07,2.13)$ & $0.04(-0.11,0.64)$ \\
Co-viewing with parents & $4.44(2.90,5.98)$ & 0.16 \\
Parental modeling & $1.81(0.42,3.20)$ & $<0.001$ \\
Access to screens & $-1.39(-2.47,-0.31)$ & 0.01 \\
Perceived opportunities for PA in neighborhood & & 0.01 \\
\hline
\end{tabular}

Results obtained from multiple linear regression analyses Gender, age and parental education adjusted for in the analyses $P A$ physical activity 
Table 3 Mediators of the association between parental education and total screen time among adolescents

\begin{tabular}{|c|c|c|c|c|c|}
\hline & c-path & $c^{\prime}$-path & a-path & b-path & $a b$ \\
\hline Parental modeling & & & $\begin{array}{l}-0.22(-0.34,- \\
0.09)\end{array}$ & $4.63(3.10,6.16)$ & $-1.10(-1.76,-0.34)$ \\
\hline Self-efficacy to limit electronic games & & & $0.69(0.09,1.30)$ & $\begin{array}{l}-1.17(-1.53,- \\
0.80)\end{array}$ & $\begin{array}{l}-0.81(-1.69,- \\
1.39)\end{array}$ \\
\hline $\mathrm{TV} /$ movie streaming during dinner & & & $\begin{array}{l}-0.37(-0.57,- \\
0.17)\end{array}$ & $1.10(0.08,2.12)$ & $\begin{array}{l}-0.41(-0.97,- \\
0.01)\end{array}$ \\
\hline Access to screens & & & $\begin{array}{l}-0.21(-0.35,- \\
0.07)\end{array}$ & $1.93(0.55,3.32)$ & $\begin{array}{l}-0.40(-0.84,- \\
0.07)\end{array}$ \\
\hline \multirow[t]{2}{*}{$\begin{array}{l}\text { Perceived opportunities for PA in } \\
\text { neighborhood }\end{array}$} & & & $0.22(0.04,0.40)$ & $\begin{array}{l}-1.33(-2.41,- \\
0.24)\end{array}$ & $\begin{array}{l}-0.29(-0.78,- \\
0.01)\end{array}$ \\
\hline & $-6.97(-9.71,-4.22)$ & $-3.39(-5.89,-0.89)$ & & & \\
\hline
\end{tabular}

Significant mediators shown

All paths were adjusted for gender and age

Ref. category: low parental education

$P A$ physical activity

modeling, eating meals in front of the TV and access to screens (namely bedroom TV) among youth have previously been documented in a systematic review of the literature in which most studies used parental education as an indicator of SEP [13]. Self-efficacy to engage in healthier behaviors among adolescents such as healthier dietary behaviors has been found to differ by parental educational level [30,31]; the same was found to be true for self-efficacy to limit screen activities. In addition, in the present study, perceived opportunities for PA in the neighborhood and neighborhood PA facilities were also found to differ by SEP, being more favorable among those with a higher SEP. There are multiple levels of influence on health behaviors, as postulated by the social ecological model [12]. The results of this study highlight differences at individual, interpersonal and perceived environmental levels that make it difficult for those with a lower socioeconomic position to engage in more favorable behaviors.

Most of the correlates that varied by socioeconomic position were found to mediate socioeconomic differences in TST. These factors represent important entry points for interventions to limit screen time and tackle socioeconomic differences. However, existing evidence from interventions and from qualitative studies indicate the multiple challenges that exist when trying to address screen time among youth. Systematic reviews of the literature indicate that the impact of interventions on reducing screen time among youth is either limited [32, 33] or absent [34]. Factors such as the strong habitual component of SB and the high accessibility and appeal of screen time (in particular in an age of high technological advances) have been incriminated for the lack of effect of interventions [32]. Systematic synthesis of qualitative evidence also indicates that screen time is an established norm among youth, which represents a significant obstacle for interventions [35]. Effective and multilevel approaches are thus needed to address screen time. Parental modelling was found to be an important correlate and an important mediator of socioeconomic differences in TST in the present study. Qualitative research evidence suggests that parents engage in screenbased SB even though they recognize that it is important to reduce the screen time of youth [35]. It is thus important to emphasize to parents that efforts aimed at reducing screen time also require their active participation. The findings of the study also suggest that restricting access to screens could be a potential strategy to reduce screen time and related social inequalities among adolescents. However, qualitative evidence indicates that restricting such access, in particular the removal of bedroom TV, can be met with substantial opposition namely among adolescents [36]. Participants also indicated that not putting a TV in the child's bedroom would be easier than removing one that was already in place [36]. These findings indicate that avoiding excessive exposure to screens should start early in childhood. Screen viewing during meals, in particular during dinner, was also found to be associated with a higher screen time and mediated socioeconomic differences in screen time. The literature shows that parental education is positively related to having family meals [37], which is inversely related to TV viewing during meals [38], which might in part explain the findings of the study. One of the strategies to reduce screen use during meals can therefore be the promotion of family meals, in particular among those with a lower socioeconomic position.

The perceived opportunities for PA in the neighborhood were also found to predict screen time and mediate socioeconomic differences. SBs and PA are not opposite sides of the same coin. However small inverse associations between the behaviors are documented in the literature [39]. Indeed, if no social or physical 
opportunities for engaging in PA around the home and in the neighborhood exist, the alternative option in this day of developing social media and technological development is likely going to be more engagement in screen time. In this regard, research evidence shows that youth report higher involvement in screen activities when they perceive a lack of peer social support networks [35]. In line with the findings of the study, qualitative interviews with both parents and adolescents indicate that a lack of physical opportunities to engage in PA near the home can result in a higher screen time [35]. These results reflect that efforts by policy makers towards improvement of neighborhood PA opportunities would also benefit youth through the reduction of screen time, in addition to promoting PA. Such efforts might be particularly relevant for those with a lower socioeconomic position among whom alternative leisure-time activities that require resources are likely to be more limited.

\section{Strengths and weaknesses}

Screen-based SBs tend to co-occur (multitasking), thus TST is likely to overestimate the time that adolescents spend on screen-based activities. However, interventions are likely to target TST in general and not single screenbased activities. Thus, TST was used as an outcome in the present study. However, future studies with measures accounting for the multitasking behavior of adolescents are warranted, as also highlighted in a recent systematic review of the literature [1]. The use of selfreported measures is associated with problems of validity and reliability. In general, the more unreliable the measures, the higher the chance of Type II errors; that is not finding differences and associations that in fact exist. Therefore, differences and associations in the study were probably underestimated rather than overestimated. Education was the only indicator of SEP used in the current study. It was reported by parents, resulting in a low rate of missing data. Parental reports of education are also likely to be more accurate than adolescent reports. However, different indicators of SEP can reflect different social, material and financial assets that can influence behavior. Thus, future studies including other indicators of SEP are warranted to explore whether the association between SEP and TST is indicator-specific. The age range of participants is narrow and the results might thus namely be applicable to younger adolescents, although the correlates and mediators identified are relevant for older adolescents as well.

The inclusion of a broad range of SBs including behaviors relevant for contemporary youth is a strength of the study. Several modifiable correlates and mediators were also included, addressing a gap in the existing literature. The sample size was relatively large, and a good response rate was achieved.

\section{Conclusions}

The study identified several modifiable factors at the individual, interpersonal and perceived environmental levels that can be targeted in interventions aimed at decreasing screen time among youth in general and among those with a low socioeconomic position in particular. More correlates of TST and more mediators of socioeconomic differences in screen time should be explored in future studies. These studies should be complemented with qualitative in-depth exploration of the multiple interacting factors that act as barriers and facilitators of screen time, in particular among those with a lower socioeconomic position.

\section{Abbreviations \\ SEP: Socioeconomic position; SB: Sedentary behavior; TST: Total screen time; TV: Television}

\section{Acknowledgements}

The ESSENS study was a collaborative project between the Oslo Metropolitan University and the public health project Folkehelseforum $\varnothing$ vre Romerike (FØR). We would like to thank all the participants who took part in this study.

\section{Ethical approval and consent to participate}

The study was approved by the Norwegian Centre for Research Data (44,365/3/AGL). Written informed consent was obtained from all parents of participating adolescents; adolescents provided assent.

\section{Authors' contributions}

MKG designed the study, led the project planning and implementation, participated in data collection, conducted the data analyses and wrote the first draft of this manuscript. LET, SH and LT contributed to the planning and implementation of the study. All authors have critically read and approved the final version of the manuscript.

\section{Funding}

The ESSENS study received internal funding from the Oslo Metropolitan University. MKG is supported by funding from the Research Council of Norway $(273823 / \mathrm{H} 10)$

\section{Availability of data and materials}

The datasets used in the current study are available from the corresponding author on reasonable request.

\section{Consent for publication}

Not applicable.

\section{Competing interests}

The authors declare that they have no competing interests.

\section{Author details}

${ }^{1}$ Department of Nutrition, Institute of Basic Medical Sciences, University of Oslo, P.O.Box 1046, Blindern, 0317 Oslo, Norway. ${ }^{2}$ Department of Nursing and Health Promotion, Faculty of Health Sciences, OsloMet - Oslo Metropolitan University, 0130 Oslo, Norway.

Received: 12 February 2020 Accepted: 29 May 2020

Published online: 05 June 2020

\section{References}

1. Sedentary Behaviour Research Network. Letter to the editor: standardized use of the terms "sedentary" and "sedentary behaviours". Appl Physiol Nutr Metab. 2012;37:540-2.

2. Thomas G, Bennie JA, De Cocker $K$, et al. A descriptive epidemiology of screen-based devices by children and adolescents: a scoping review of 130 surveillance studies since 2000. Child Indic Res. 2019:1-16. 
3. Carson V, Hunter S, Kuzik N, Gray CE, Poitras VJ, Chaput JP, Saunders TJ, Katzmarzyk PT, Okely AD, Connor Gorber S, Kho ME, Sampson M, Lee H, Tremblay MS. Systematic review of sedentary behaviour and health indicators in school-aged children and youth: an update. Appl Physiol Nutr Metab. 2016;41:S240-65.

4. Biddle SJ, García Bengoechea E, Wiesner G. Sedentary behaviour and adiposity in youth: a systematic review of reviews and analysis of causality. Int J Behav Nutr Phys Act. 2017;14:43.

5. Biddle SJ, Pearson N, Ross GM, Braithwaite R. Tracking of sedentary behaviours of young people: a systematic review. Prev Med. 2010;51:345-51.

6. Salmon J, Tremblay MS, Marshall SJ, Hume C. Health risks, correlates, and interventions to reduce sedentary behavior in young people. Am J Prev Med. 2011;41:197-206.

7. Hoyos Cillero I, Jago R. Systematic review of correlates of screen-viewing among young children. Prev Med. 2010;51:3-10.

8. Xu H, Wen LM, Rissel C. Associations of parental influences with physical activity and screen time among young children: a systematic review. Obes. 2015;2015:546925.

9. Pate RR, Mitchell JA, Byun W, Dowda M. Sedentary behaviour in youth. Br J Sports Med. 2011;45:906-13.

10. van der Horst K, Paw MJ, Twisk JW, Van Mechelen W. A brief review on correlates of physical activity and sedentariness in youth. Med Sci Sports Exerc. 2007;39:1241-50

11. Parajára MDC, de Castro BM, Coelho DB, Meireles AL. Are neighborhood characteristics associated with sedentary behavior in adolescents? A systematic review. Int J Environ Health Res. 2019;31:1-21.

12. Sallis JF, Owen N, Fisher EB. In: Glanz Z, Rimer BK, Viswanath K, editors. Ecological models of health behaviour. In: health behaviour and health education. Theory, research and practice. 4th ed. San Francisco: Jossey-Bass; 2008.

13. Gebremariam MK, Altenburg TM, Lakerveld J, Andersen LF, Stronks K, Chinapaw MJ, Lien N. Associations between socioeconomic position and correlates of sedentary behaviour among youth: a systematic review. Obes Rev. 2015;16:988-1000

14. Gebremariam MK, Lien N, Nianogo RA, Arah OA. Mediators of socioeconomic differences in adiposity among youth: a systematic review. Obes Rev. 2017;18:880-98.

15. Pearl J. Causality: models, reasoning and inference. Cambridge: Cambridge University Press; 2000.

16. World Health Organization. Closing the gap in a generation. Health equity through action on the social determinants of health. Final Report of the Commission on Social Determinants of Health. Geneva: World Health Organization; 2008.

17. Tandon PS, Zhou C, Sallis JF, Cain KL, Frank LD, Saelens BE. Home environment relationships with children's physical activity, sedentary time, and screen time by socioeconomic status. Int J Behav Nutr Phys Act. 2012;9: 88.

18. Singh AS, Vik FN, Chinapaw MJ, Uijtdewilligen L, Verloigne M, FernándezAlvira JM, Stomfai S, Manios Y, Martens M, Brug J. Test-retest reliability and construct validity of the ENERGY-child questionnaire on energy balancerelated behaviours and their potential determinants: the ENERGY-project. Int J Behav Nutr Phys Act. 2011:8:136.

19. Lien $\mathrm{N}$, Bjelland $\mathrm{M}$, Bergh $\mathrm{H}_{1}$, Grydeland $\mathrm{M}$, Anderssen $\mathrm{SA}$, Ommundsen $\mathrm{Y}$, Andersen LF, Henriksen HB, Randby JS, Klepp Kl. Design of a 20-month comprehensive, multicomponent school-based randomised trial to promote healthy weight development among 11-13 year olds: the HEalth in adolescents study. Scand J Public Health. 2010;38:38-51.

20. Jago R, Baranowski T, Watson K. Development of new physical activity and sedentary behavior change self-efficacy questionnaires using item response modeling. Int J Behav Nutr Phys Act. 2009;6:20.

21. Ommundsen Y, Page A, Ku PW, Cooper AR. Cross-cultural, age and gender validation of a computerised questionnaire measuring personal, social and environmental associations with children's physical activity: the European youth heart study. Int J Behav Nutr Phys Act. 2008:5:29.

22. Preacher KJ, Hayes AF. Asymptotic and resampling strategies for assessing and comparing indirect effects in multiple mediator models. Behav Res Methods. 2008;40:879-91

23. Yamada M, Sekine M, Tatsuse T. Parental internet use and lifestyle factors as correlates of prolonged screen time of children in Japan: results from the super Shokuiku school project. J Epidemiol. 2018;28:407-13.
24. Hesketh K, Ball K, Crawford D, Campbell K, Salmon J. Mediators of the relationship between maternal education and children's TV viewing. Am J Prev Med. 2007;33:41-7.

25. Bandura A. Social foundations of thought and action: a social cognitive theory. Englewood Cliffs: Prentice-Hall; 1986

26. Timperio A, Salmon J, Ball K, Saskia J, Brug J, Crawford D. Neighborhood characteristics and TV viewing in youth: nothing to do but watch TV? J Sci Med Sport. 2012;15:122-8.

27. Forsyth A, Wall M, Choo T, Larson N, Van RD, Neumark-Sztainer D. Perceived and police reported neighborhood crime: linkages to adolescent activity behaviors and weight status. J Adolesc Health. 2015;57:87-92.

28. Kalish M, Banco L, Burke G, Lapidus G. Outdoor play: a survey of parent's perceptions of their child's safety. J Trauma. 2010;69:S218-22.

29. Datar A, Nicosia N, Shier V. Parent perceptions of neighborhood safety and children's physical activity, sedentary behavior, and obesity: evidence from a national longitudinal study. Am J Epidemiol. 2013;177:1065-73.

30. Ball K, MacFarlane A, Crawford D, Savige G, Andrianopoulos N, Worsley A. Can social cognitive theory constructs explain socio-economic variations in adolescent eating behaviours? A mediation analysis. Health Educ Res. 2009; 24:496-506.

31. Lehto E, Ray C, Te Velde S, Petrova S, Duleva V, Krawinkel M, Behrendt I, Papadaki A, Kristjansdottir A, Thorsdottir I, Yngve A, Lien N, Lynch C, Ehrenblad B, Vaz de Almeida MD, Ribic CH, Simčic I, Roos E. Mediation of parental educational level on fruit and vegetable intake among schoolchildren in ten European countries. Public Health Nutr. 2015;18:89-99.

32. Biddle SJ, Petrolini I, Pearson N. Interventions designed to reduce sedentary behaviours in young people: a review of reviews. Br J Sports Med. 2014;48: 182-6.

33. Maniccia DM, Davison KK, Marshall SJ, Manganello JA, Dennison BA. A metaanalysis of interventions that target children's screen time for reduction. Pediatrics. 2011:128:e193-210.

34. Wahi G, Parkin PC, Beyene J, Uleryk EM, Birken CS. Effectiveness of interventions aimed at reducing screen time in children: a systematic review and meta-analysis of randomized controlled trials. Arch Pediatr Adolesc Med. 2011;165:979-86.

35. Minges KE, Owen N, Salmon J, Chao A, Dunstan DW, Whittemore R. Reducing youth screen time: qualitative metasynthesis of findings on barriers and facilitators. Health Psychol. 2015;34:381-97.

36. Jordon AB, Hersey JC, McDivitt JA, Heitzler CD. Reducing children's television-viewing time: a qualitative study of parents and their children. Pediatrics. 2006;118:e1303-10.

37. Martin-Biggers J, Spaccarotella K, Berhaupt-Glickstein A, Hongu N, Worobey J, Byrd-Bredbenner C. Come and get it! Adiscussion of family mealtime literature and factors affectingobesity risk. Adv Nutr. 2014:5:235-47.

38. Fulkerson JA, Neumark-Sztainer D, Story M. Adolescent and parent views of family meals. J Am Diet Assoc. 2006;106:526-32.

39. Pearson N, Braithwaite RE, Biddle SJ, van Sluijs EM, Atkin AJ. Associations between sedentary behaviour and physical activity in children and adolescents: a meta-analysis. Obes Rev. 2014;15:666-75.

\section{Publisher's Note}

Springer Nature remains neutral with regard to jurisdictional claims in published maps and institutional affiliations.

Ready to submit your research? Choose BMC and benefit from

- fast, convenient online submission

- thorough peer review by experienced researchers in your field

- rapid publication on acceptance

- support for research data, including large and complex data types

- gold Open Access which fosters wider collaboration and increased citations

- maximum visibility for your research: over $100 \mathrm{M}$ website views per year

At $\mathrm{BMC}$, research is always in progress.

Learn more biomedcentral.com/submission 